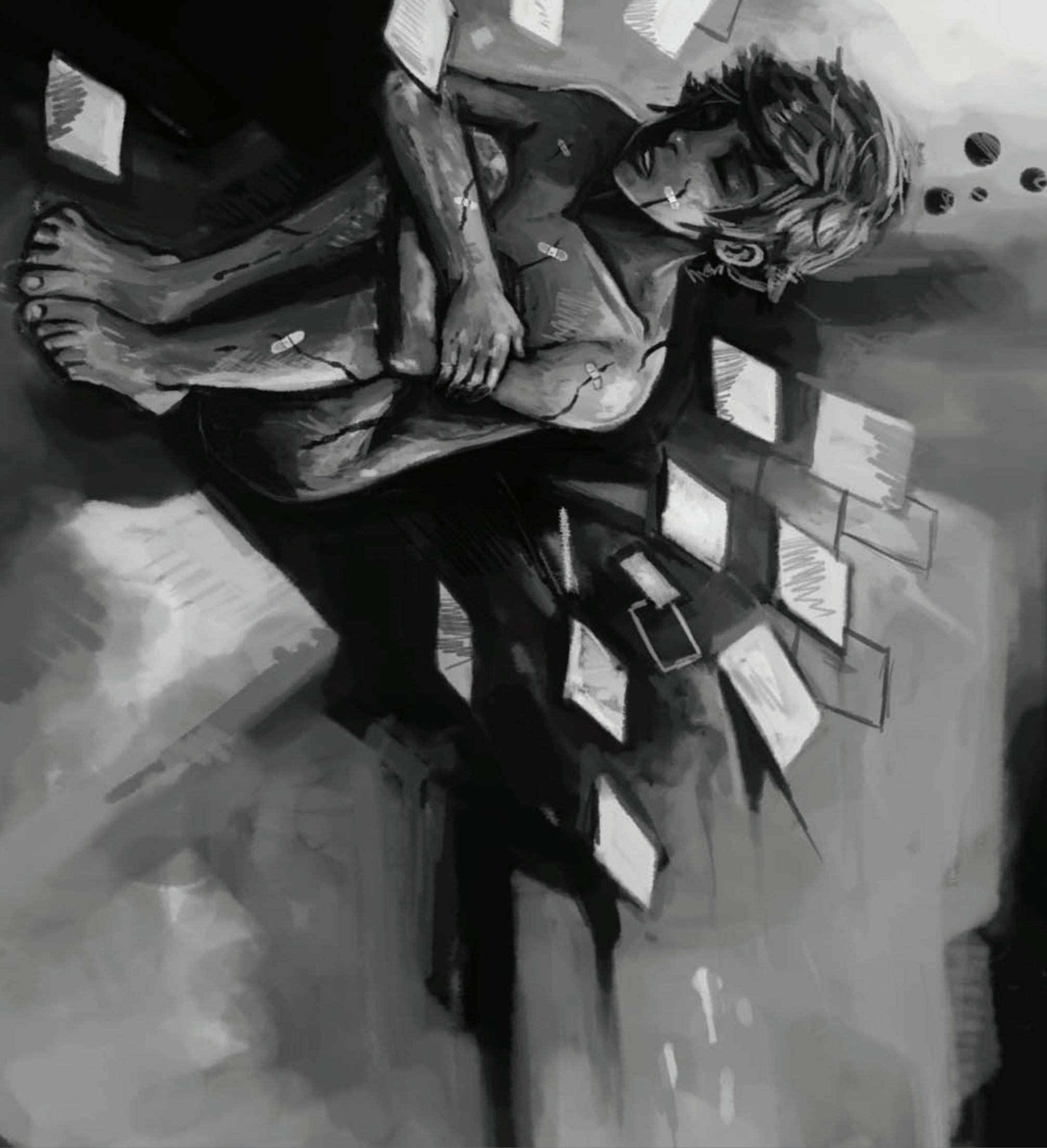

\title{
Principio de progresividad en la pensión de invalidez en la jurisprudencia constitucional colombiana
}





\section{Principio de progresividad en la pensión de invalidez en la jurisprudencia constitucional colombiana}

Principle of progressivity in disability pension in Colombian constitutional jurisprudence

\author{
Isabel Goyes Moreno (Colombia) \\ Universidad de Nariño \\ isabelgm99@yahoo.com \\ Directora Grupo de Investigación Derecho, Justicia y Región, \\ DEJURE. Docente Titular de la Facultad de Derecho de la \\ Universidad Antonio Nariño.
}

\author{
Princípio de progressividladle na pensão de \\ invalidez na jurisprudência constitucional \\ colombiana
}

\section{Resumen}

Este artículo hace referencia a la incidencia del principio de progresividad en la figura jurídica de la pensión de invalidez de origen común, gracias a cuya aplicación, la Corte Constitucional ha garantizado los postulados de igualdad, equidad, vida digna y justicia material consagrados por el constituyente primario. Con fundamento en una revisión jurisprudencial del período comprendido entre el año 2000 y el 2012, se ha establecido el sentido y alcance que la Corporación le ha otorgado a dicho principio. La descripción de las circunstancias fácticas que dieron origen a la acción de amparo constitucional en varios casos, así como las consideraciones jurídicas que sustentaron algunas acciones de inconstitucionalidad, constituyeron las fuentes por excelencia, para corroborar la validez y trascendencia del principio de progresividad en Colombia.

\begin{abstract}
This paper refers to the effect of the principle of progressivity in the legal form of the common origin disability pension, through whose application, the Constitutional Court has guaranteed the principles of equality, equity, justice and dignified life, enshrined by the constitution. Based on a review of the case law, from 2000 to 2012, it has established the meaning and scope that Corporation has granted to this principle. The description of the factual circumstances that gave rise to the amparo in several cases, as well as legal considerations that supported some unconstitutionality actions, were the ultimate sources, to verify the validity and the importance of the principle of progressivity in Colombia.
\end{abstract}

\section{Resumo}

Este artigo faz referência à incidência do princípio de progressividade na figura jurídica da pensão de invalidez de origem comum, graças a cuja aplicação, a Corte Constitucional tem garantido os postulados de igualdade, equidade, vida digna e justiça material consagrados pelo constituinte primário. Com fundamento em uma revisão jurisprudencial do período compreendido entre o ano 2000 e 2012, tem-se estabelecido o sentido e alcance que a Corporação tem-lhe outorgado a dito princípio. A descrição das circunstâncias fáticas que deram origem à ação de amparo constitucional em vários casos, assim como as considerações jurídicas que sustentaram algumas ações de inconstitucionalidade, constituiram as fontes por excelência, para corroborar a validez e transcendência do princípio de progressividade na Colômbia. 
Key words: Principle of progressivity, disability, constitutional jurisprudence
Palavras chave: Princípio de progressividade, invalidez, jurisprudência constitucional.

Palabras clave: Principio de progresividad, invalidez,

jurisprudencia constitucional

\section{Para citar este artículo/ To cite this article/ Para citar este artigo}

Goyes, Isabel (2012). Principio de progresividad en la pensión de invalidez en la jurisprudencia constitucional colombiana. Panorama, VII (12), 123 - 141. 


\section{Introducción}

La seguridad social tiene aceptación universal como derecho humano que genera obligaciones estatales, cuya dimensión es variada dependiendo tanto de la cobertura y los riesgos amparados, como de la capacidad económica de cada nación y de las políticas gubernamentales respectivas; de igual manera, todo ciudadano reclama para sí una seguridad social básica acorde con la dignidad humana. Con fundamento en dicho planteamiento han surgido voces universales que reclaman el reconocimiento de principios de la seguridad social que contribuyan a garantizar dicha aspiración.

La jurisprudencia constitucional colombiana - con fundamento en los principios consagrados en la Carta Política de 1991, así como en aquellos otros derivados de los compromisos internacionales y que se vinculan al ordenamiento jurídico mediante el bloque de constitucionalidad- ha decidido numerosas acciones de tutela y demandas de inconstitucionalidad, orientada por dichos postulados, con el propósito último de procurar la justicia material y la vida digna para todas y todos los colombianos.

La figura de la pensión de invalidez de origen común debido a las incidencias laborales, económicas y sociales que acarrea tanto para quien ha perdido su capacidad laboral como para sus familias, merece un estudio cuidadoso y un trato justo y acorde con la condición humana.

Con fundamento en una revisión de sentencias de la Corte Constitucional colombiana, se puede manifestar que frente a aquellas leyes que incrementan los requisitos para acceder a la pensión de invalidez, que crean condicionamientos más gravosos o que implican un retroceso normativo, el juez constitucional ha esgrimido el principio de progresividad con miras a otorgar el amparo impetrado, absteniéndose en algunos eventos de aplicar tales mandatos e inclusive ordenando su exclusión del ordenamiento jurídico, tal como se observará a lo largo de este escrito.

\section{El principio de progresividad}

El término principio, por su carácter polisémico y polimorfo, tiene múltiples significado y puede adoptar distintas formas, ya como norma genérica, como valor superior, como criterio de interpretación, como máxima jurídica. En todo caso,

"La discusión acerca del valor de los principios jurídicos entre el positivismo jurídico y el iusnaturalismo se enmarca en algunos de estos campos de uso de este término, específicamente, se trata a los principios como fuentes normativas y como máximas que permiten sistematizar y organizar el sistema jurídico" (Rojas, 2006, p.125).

No obstante, mientras que para los iusnaturalistas los principios son universales, inalienables e inmodificables, para los positivas se conciben como temporales, modificables y fruto del consenso social; pues unos y otros coinciden en aceptar su importancia para dar coherencia a todo el ordenamiento jurídico, así como para servir de hilo conductor en la hermenéutica de todo el contenido del sistema jurídico que se trate. 
En el siglo XX, a partir de los procesos de constitucionalización de la Carta de Derechos Humanos, los principios adquirieron reconocimiento normativo. De ahí que en la actualidad tengan presencia en el sistema de Naciones Unidas, en el regional interamericano, en el de países andinos y en la Organización Internacional del Trabajo (OIT), no solo como principios sino también como derechos fundamentales, así como en las constituciones de casi todos los países de América Latina.

El principio de progresividad está referenciado en el Pacto Internacional de Derechos Económicos, Sociales y Culturales (Naciones Unidas, 1966) -PIDESC- y en el Protocolo Adicional a la Convención Americana sobre Derechos Humanos en materia de derechos económicos, sociales y culturales (Organización de Estados Americanos, 1988), el Protocolo de San Salvador, mencionar solo los dos más importantes.

En efecto, la Organización de las Naciones Unidas (1966) a través del Preámbulo del PIDESC,reconoce de manera expresa que:

“ [...] con arreglo a la Declaración Universal de Derechos Humanos, no puede realizarse el ideal del ser humano libre, liberado del temor y de la miseria, a menos que se creen condiciones que permitan a cada persona gozar de sus derechos económicos, sociales y culturales, tanto como de sus derechos civiles y políticos" ( ONU 1966-1976), con lo cual les otorga a estos derechos el mismo nivel de los derechos de civiles, superando aquella indebida diferenciación entre derechos de primera y segunda generación”.

Estas y otras consideraciones, llevan a los Estados Partes a consagrar en el artículo 2, numeral 1, obligaciones perentorias y progresivas, al expresar que:

"Cada uno de los Estados Partes en el presente Pacto se comprometen adoptar medidas, tanto por separado como mediante la asistencia y la cooperación internacionales, especialmente económicas y técnicas, hasta el máximo de los recursos de que disponga, para lograr progresivamente, por todos los medios apropiados, inclusive en particular la adopción de medidas legislativas, la plena efectividad de los derechos aquí reconocidos". Y este es el fundamento del principio de progresividad que debe acompañar a los Derechos Económicos, Sociales y Culturales (DESC).

En relación con la seguridad social el artículo 9 ordenó: "Los Estados Partes en el presente Pacto reconocen el derecho de toda persona a la seguridad social, incluso al seguro social"(ONU, 1966). Como puede establecerse del texto del Pacto, la seguridad social forma parte de los DESC y estos derechos están amparados y garantizados por la progresividad.

Los principios de Limburgo (1986) sobre la aplicación del PIDESC fueron contundentes en indicar que

“cada uno de los Estados comprometidos con el PIDESC a partir de su entrada en vigencia, 1976, se obligaban de conformidad con el artículo 17, a hacer uso, a nivel nacional, de todos los medios apropiados, tales como medidas legislativas, judiciales, administrativas, económicas, sociales y educativas consistentes en la naturaleza de los derechos, con el fin de cumplir con las obligaciones por ellos aceptadas bajo el Pacto. Cualquier medida regresiva debía estar ampliamente justificada en la conveniencia de la colectividad". 
En el continente americano, el protocolo adicional a la Convención Americana sobre los Derechos Humanos, se realizó mediante el Protocolo de San Salvador (1988), el cual se refiere a la relación existente entre los derechos económicos, sociales y culturales y la de los derechos civiles y políticos, afirmando que todos esos derechos "constituyen un todo indisoluble que encuentra su base en el reconocimiento de la dignidad de la persona humana, por lo cual exigen una tutela y promoción permanente con el objeto de lograr su vigencia plena, sin que jamás pueda justificarse la violación de unos en aras de la realización de otros". De esta forma, se ratifica por parte de los países de América, la indivisibilidad de los derechos humanos, cualquiera sea su naturaleza.

La responsabilidad de los Estados frente a los DESC se evidencia con el texto del artículo l que ordena:

“.... adoptar las medidas necesarias tanto de orden interno como mediante la cooperación entre los Estados, especialmente económica y técnica, hasta el máximo de los recursos disponibles y tomando en cuenta su grado de desarrollo, a fin de lograr progresivamente, y de conformidad con la legislación interna, la plena efectividad de los derechos que se reconocen en el presente Protocolo"(OEA, 1988).

Al igual que en el sistema universal a nivel regional también se consagró el principio de progresividad.

Por su parte, el artículo 9 se ocupa del tema de la seguridad social en estos términos:

"Toda persona tiene derecho a la seguridad social que la proteja contra las consecuencias de la vejez y de la incapacidad que la imposibilite física o mentalmente para obtener los medios para llevar una vida digna y decorosa. En caso de muerte del beneficiario, las prestaciones de seguridad social serán aplicadas a sus dependientes.Cuando se trate de personas que se encuentran trabajando, el derecho a la seguridad social cubrirá al menos la atención médica y el subsidio o jubilación en casos de accidentes de trabajo o de enfermedad profesional $y$, cuando se trate de mujeres, licencia retribuida por maternidad antes y después del parto" (OEA, 1988).

El Comité para la supervisión de los derechos económicos, sociales y culturales de las Naciones Unidas, creado en 1985, tiene la misión de recepcionar los informes presentados por los diversos países dos años después de la respectiva ratificación y cada cinco años en adelante, ha precisado que la obligatoriedad de avanzar en los DESC, obliga a evaluar con el mayor rigor, todas aquellas medidas de índole deliberadamente retroactiva, las que sólo se admitirán cuando puedan justificarse plenamente en el ámbito del mejoramiento colectivo(Observación General núm. 3).

De conformidad con la normatividad internacional transcrita, los Estados están obligados a avanzar en la implementación y desarrollo de los DESC, en virtud del principio de progresividad que les es inherente, Ahora bien, dado que la seguridad social es uno de los derechos económicos, sociales y culturales más importantes, es evidente que la realización de la pensión de invalidez a favor de quienes, por razones diferentes a los accidentes de trabajo y las enfermedades laborales, han disminuido su capacidad laboral, se convierte en un expresión de justicia social y material. 


\section{Regulación normativa de la pensión de invalidez}

La invalidez es un riesgo que acecha a cualquier persona económica y socialmente activa, generando una minusvalía en su posibilidad de generar ingresos para mantener su condición de vida digna. Por esta razón, fue una de las primeras contingencias que mereció la atención de los Estados, a ellas se hace referencia cuando se dictan normas especiales a favor de las víctimas de los conflictos internos, cuyas secuelas implicaron para algunos Jefes militares, incapacidades permanentes en su capacidad laboral.

La invalidez puede derivarse de enfermedades generales o de accidentes ajenos a la vida laboral; así mismo hay pérdidas de la capacidad laboral que tienen su origen tanto en la naturaleza de la labor desempeñada como en un accidente ocurrido en el sitio del trabajo o con ocasión del mismo. Este análisis se concreta en la primera circunstancia, denominada invalidez de origen común, circunstancia que requiere: i) pérdida de la capacidad laboral del 50\% o más, por cualquier causa de origen no profesional ii) calificación de dicha invalidez, y iii) que la misma no hubiese sido provocada intencionalmente. El trámite de calificación se regula por el artículo 38 de la Ley 100 de 1993 y al artículo 52 de la Ley 962 de 2005, que modificó el artículo 41 de la Ley 100 de 1993.

La pérdida de la capacidad laboral (artículo 7 Decreto 917 de 1999), se mide en función de la deficiencia, discapacidad y minusvalía sufrida, conceptos que tienen sus respectivas ponderaciones porcentuales. A continuación se incluye una tabla que sintetiza los principales aspectos normativos de la pensión de invalidez común. 


\section{Principales aspectos normativos de invalidez común}

\begin{tabular}{|c|c|c|c|c|}
\hline & Acuerdo 049 & Ley 100 de 1993 & $\begin{array}{l}\text { Ley } 797 \text { de } 2003 \\
29 \text { de enero }\end{array}$ & $\begin{array}{l}\text { Ley } 860 \text { de } 2003 \\
\text { diciembre } 26\end{array}$ \\
\hline Requisitos & $\begin{array}{l}\text { Art. } 6 \\
150 \text { semanas dentro } \\
\text { de los } 6 \text { años ante- } \\
\text { riores a la fecha del } \\
\text { estado de invalidez, } \\
0300 \text { semanas en } \\
\text { cualquier época con } \\
\text { anterioridad al estado } \\
\text { de invalidez. } \\
\text { Artículo } 3 \text { Decreto } \\
917 \text { de 1999. Fecha } \\
\text { de estructuración de } \\
\text { invalidez. }\end{array}$ & $\begin{array}{l}\text { Art. } 39 \\
\text { Que la persona esté } \\
\text { cotizando y haya } \\
\text { cotizado por lo menos } \\
26 \text { semanas. } \\
\text { Que habiendo dejado } \\
\text { de cotizar tenga } \\
\text { cotizadas mínimo26 } \\
\text { semanas en el año } \\
\text { inmediatamente } \\
\text { anterior al estado de } \\
\text { invalidez. }\end{array}$ & $\begin{array}{l}\text { Art. } 11 \\
\text { (Inexequible C- } 1056 \\
\text { del } 11 \text { de noviembre de } \\
2003 \text { ). } \\
\text { Invalidez causada } \\
\text { por enfermedad y } \\
\text { accidente: } 50 \text { semanas } \\
\text { en los últimos 3años } \\
\text { inmediatamente } \\
\text { anteriores a la fecha } \\
\text { de estructuración y su } \\
\text { fidelidad de cotización } \\
\text { para con el sistema } \\
\text { sea al menos del } 25 \% \\
\text { del tiempo transcurrido } \\
\text { entre el momento en } \\
\text { que cumplió } 20 \text { años } \\
\text { de edad y la fecha de la } \\
\text { primera calificación del } \\
\text { estado de invalidez. } \\
3 \text { años anteriores al } \\
\text { hecho causante de la } \\
\text { misma. } \\
\text { En la Ley } 797 \text { en la } \\
\text { invalidez causada } \\
\text { por accidente, no se } \\
\text { exigía el requisito de la } \\
\text { fidelidad. }\end{array}$ & $\begin{array}{l}\text { Art. } 39 \text { y art. 1. Ley } 860 \text { de } \\
2003 . \\
\text { Invalidez causada por } \\
\text { enfermedad: } \\
\text { Invalidez causada por } \\
\text { accidente: Que haya coti- } \\
\text { zado } 50 \text { semanas dentro } \\
\text { de los últimos } 3 \text { años } \\
\text { inmediatamente anteriores } \\
\text { al hecho causante de la } \\
\text { misma, y una fidelidad de } \\
\text { cotización del veinte por } \\
\text { ciento } 20 \% \text { entre los } 20 \\
\text { años de edad y la fecha de } \\
\text { la primera calificación del } \\
\text { estado de invalidez. } \\
\text { Menor de } 20 \text { años de } \\
\text { edad, } 26 \text { semanas. } \\
\text { Cuando el afiliado haya } \\
\text { cotizado por lo menos } \\
\text { el } 75 \% \text { de las semanas } \\
\text { mínimas requeridas para } \\
\text { acceder a la pensión de } \\
\text { vejez, solo se requerirá } \\
\text { que haya cotizado } 25 \\
\text { semanas en los últimos } 3 \\
\text { años. }\end{array}$ \\
\hline Monto & \multicolumn{4}{|c|}{$\begin{array}{l}\text { Básico } \\
500 \text { semanas }=45 \% \\
\text { Adicional } \\
1,5 \% \text { por cada } 50 \text { semanas por incapacidad igual o superior al } 50 \% \text { e inferior al } 66 \% \\
800 \text { semanas }=54 \% \\
\text { Adicional } \\
2 \% \text { porcada } 50 \text { semanas por incapacidad igual o superior al } 66 \%\end{array}$} \\
\hline I.B.L. & \multicolumn{4}{|c|}{$\begin{array}{l}\text { Promedio de los salarios o rentas sobre los cuales el afiliado ha cotizado durante los } 10 \text { años anteriores } \\
\text { reconocimiento de la pensión, actualizado anualmente con el IPC o durante todo el tiempo de invalidez. }\end{array}$} \\
\hline Mesadas & \multicolumn{4}{|l|}{14} \\
\hline Revision & \multicolumn{4}{|c|}{$\begin{array}{l}\text { Cada } 3 \text { años a solicitud de la entidad que reconoce la pensión o en cualquier tiempo a solicitud del } \\
\text { pensionado. }\end{array}$} \\
\hline
\end{tabular}

Cuadro 1. Fuente: Goyes, I., Higaldo, M. (2007). Principios de la seguridad social en Pensiones. Pasto: Universidad de Nariño. 
Tanto en el régimen de prima media como en el de ahorro individual, los requisitos y exigencias son los mismos, y se gobiernan por el artículo 38 de la Ley 100 de 1993, el artículo 1 de la Ley 860 de 2003 que modificó el artículo 39 de la Ley 100 de 1993, el artículo 40 de la Ley 100 y el artículo 52 de la Ley 952 de 2005 que modificó el artículo 41 de la Ley 100 de 1993, modificado a su vez por el artículo 142 del Decreto 19 de 2012. En el evento de no reunir las condiciones exigidas por la normativa, procede la indemnización sustitutiva o la devolución de saldos, según el régimen que se trate. Aunque en el Regímen de Ahorro Individual (RAI), se puede mantener la cuenta individual para aspirar a la pensión de vejez.

La pensión de invalidez es incompatible con la de vejez, pero no con las prestaciones provenientes del sistema de Riesgos Profesionales.

\section{Revisión jurisprudencial sobre el principio de progresividad}

Este escenario constitucional se construyó con aquellos patrones fácticos en los cuales se ve envuelta una persona que ha perdido su capacidad laboral por enfermedad o accidente de origen común; esto es, aquellas contingencias no relacionadas con la actividad laboral. Se pone de presente con este escenario el deber de solidaridad que corresponde accionar ante la pérdida de la posibilidad productiva de un ser humano, razón por la cual, se analizan conflictos que versan sobre la frustración del acceso a esta prestación económica por razones como la regresividad normativa al establecer nuevas o más gravosas condiciones y la aplicación de interpretaciones que lejos de amparar a los discapacitados obstruyen su posibilidad de contar con un sustento vital.

Los pronunciamientos jurisprudenciales de la Corte Constitucional sobre la pensión de invalidez por riesgo común, recurren a la aplicación de principios, con la finalidad de hacer efectivos los derechos de la seguridad social; esta afirmación se evidencia con lo acontecido en torno al principio de progresividad y favorabilidad que operan de manera conjunta en esta materia, y que resulta ser el que con mayor frecuencia se cita a efectos de resolver problemas jurídicos.

Los pronunciamientos jurisprudenciales que involucran el principio de la progresividad en pensión de invalidez comienzan tarde por la ruptura interpretativa frente a otros principios, cobrando autonomía y convirtiéndose en la práctica, en un límite al legislador quien en materia de seguridad social goza de amplia configuración; razón por la cual, la numerosa, dispersa y coyuntural normatividad generaba garantías a los posibles receptores pensionales a través del principio de favorabilidad.

Como se verá a través de diversas sentencias, en la jurisprudencia colombiana, el principio de progresividad es un desarrollo del principio de favorabilidad, de donde la diferencia radica en que el primero impide la expedición de leyes regresivas, mientras que el segundo, morigera el efecto de leyes existentes, ambiguas y confusas; pero confluyendo los dos principios cuando se está frente a regímenes de transición y leyes derogadas más favorables. 
Así, la sentencia T-1133 de 2000, M.P. Carlos Gaviria Díaz, resuelve la situación de un afiliado del ISS, quien solicitó su pensión de invalidez, obteniendo su reconocimiento año y medio más tarde, pero en dicho acto se le informa sobre su desafiliación del sistema de salud por no cotizar durante el tiempo que duró el trámite y que no puede volverse a afiliar al ISS, procediendo a descontar aportes para salud a favor de COMFENALCO. Tal hecho condujo a que el actor viera frustrada la prestación de servicio de salud, por haber perdido la antigüedad en el sistema.

La Corte con fundamento en el principio de favorabilidad resuelve la duda interpretativa generada frente al artículo 17 de la Ley 100 de 1993, según el cual "la obligación de cotizar cesa al momento en que el afiliado reúna los requisitos para acceder a la pensión mínima de vejez, o cuando el afiliado se pensione por invalidez o anticipadamente”. La Corte consideró que la interpretación más favorable era contraria a la acogida por el ISS según la cual, la obligación de cotizar para los pensionados por invalidez cesa cuando queda en firme el acto administrativo que la confiere y no cuando reúne los requisitos para adquirirla. En consecuencia, ordena al ISS que en las 48 horas siguientes restablezca la afiliación del patente y sus beneficiarios, quienes continuarán gozando de la antigüedad que nunca debieron perder.

En sentencia T-290 de 2005, M.P. Marco Gerardo Monroy Cabra, trata la situación de un pensionado por invalidez, quien accede a tal derecho conforme a las reglas de la convención colectiva vigente en Puertos de Colombia, según la cual el porcentaje de pérdida de la capacidad laboral debía ser del 66\%, prestación que obtuvo antes de entrar a regir la Ley 100 de 1993. El Ministerio de la Protección Social-Pasivo Social de Puertos de Colombia ordena el examen de revisión de la capacidad laboral, la cual se estableció en un 50\%; razón por la cual, se suspende la pensión de invalidez.

La Corte al estudiar el caso, el cual sopesa la norma convencional frente al contenido del artículo 38 de la Ley 100 de 1993 establece que la pensión de invalidez se adquiere con la pérdida del 50\% o más de la capacidad laboral, concluyendo así:

\begin{abstract}
"En otras palabras aunque la invalidez del demandante se originó cuando la Ley 100 de 1993 no había nacido a la vida jurídica, aquella se ha prolongado incluso hasta después de su expedición, por lo que la concesión de la pensión de invalidez causada después de esa fecha debe regirse por las normas de la ley entrante. Esto, entre otras cosas, en aplicación del principio mismo de la favorabilidad, que consagra la Constitucional Política en su artículo 53".
\end{abstract}

Luego, en la sentencia T-1291 de 2005, M.P. Clara Inés Vargas Hernández, amparó los derechos fundamentales a la seguridad social de una madre cabeza de familia quien, debido a la ocurrencia de un accidente, sufrió una incapacidad que ascendía al porcentaje del $69,05 \%$ y a quien le había sido negada la pensión de invalidez por no cumplir con la totalidad de los requisitos establecidos en la Ley 860 de 2003.

En dicha oportunidad, la Corte señaló que si bien la decisión adoptada por la entidad demandada se ajustaba formalmente al texto legal, se revelaba contraria a la Constitución y al principio de progresividad que informa el desarrollo del derecho a la seguridad social; razón por la cual aplicó la excepción de inconstitucionalidad, y dio paso al empleo de la regulación previa a la Ley 860 de 2003. 
Por otra parte, ante la ausencia de un régimen de transición en la pensión de invalidez y conforme al principio de favorabilidad, se consideró necesario dar aplicación para el caso concreto, al numeral 1 del artículo 39 de la Ley 100 de 1993, debido a que los requisitos previstos por esta norma son cumplidos cabalmente por la peticionaria. Por lo tanto, ordenó el reconocimiento y pago de la pensión de invalidez.

Por medio de la sentencia T-043 de 2007, M.P. Jaime Córdoba Triviño, la estudió tres casos en los cuales se negó la pensión de invalidez, debido a que dos de ellos no cumplían con el requisito de fidelidad al sistema, mientras que el tercero carecía del requisito de las 50 semanas cotizadas durante los últimos 3 años, anteriores a la fecha de estructuración de invalidez. La Corte concluyó al respecto:

\begin{abstract}
“...] Sin embargo, cuando el legislador adopta medidas que de cara a la antigua legislación implica un retroceso en su ámbito de protección, dichas medidas son constitucionalmente problemáticas por contradecir el principio de progresividad. Por lo tanto, frente a una medida regresiva debe presumirse su inconstitucionalidad prima facie, que podrá desvirtuarse cuando se logre establecer: (i) que la medida se encuentra justificada y ajustada al principio de proporcionalidad; (ii) que la medida no desconoce situaciones particulares y concretas consolidadas bajo la legislación anterior, por lo que se muestra respetuosa de los derechos adquiridos; o que (iii) si bien afecta a situaciones ya consolidadas, contempla otros mecanismos, como los regímenes de transición, dirigidos a proteger los derechos adquiridos o expectativas legítimas".
\end{abstract}

Frente al caso concreto, consideró que debe darse preferencia a lo fijado por el artículo 39 de la Ley 100 de 1993, en tanto permite al trabajador acceder al reconocimiento y pago de la pensión con el cumplimiento de menores requisitos. De igual manera insiste en el carácter regresivo de la Ley 860 de 2003. Dijo sobre el punto:

".... Las modificaciones legislativas al régimen de pensión de invalidez contenidas tanto en la Ley 797 de 2003 como en la Ley 860 de 2003, se muestran injustificadamente regresivas. Ello en la medida que (i) imponen requisitos más gravosos para el acceso a la prestación económica en comento; (ii) no están fundadas en razones suficientes que faculten al Congreso para disminuir el nivel de protección; (iii) afectan con una mayor intensidad a personas que por su avanzada edad y situación de discapacidad, son sujetos de especial protección por parte del Estado; y (iv) no contemplan medidas adicionales que busquen evitar la afectación desproporcionada de los intereses jurídicos de los afiliados al sistema al momento de la modificación legal, entre ellos un régimen de transición”.

Finalmente en aplicación al principio de progresividad, la Corte decide amparar sus derechos y ordena el reconocimiento de la pensión de invalidez.

La agrupación de las sentencias T- 069, M.P. Manuel Cepeda Espinosa, T-078 y T-104 de 2008, M.P. Rodrigo Escobar Gil, se fundamenta en la similitud de los hechos. En ellas, los tutelantes piden reconocimiento de la pensión de invalidez por pérdidas de la capacidad laboral del 68,7\%, 58,68\% y 61,30\%, en su orden, petición que le fue negada alegando que no cumplían con los requisitos exigidos por el artículo 1 de la Ley 860 de 2003. La Corte concede el amparo con fundamento en el artículo 39 de la Ley 100 de 1993 en su versión original.

Frente a la inexistencia de un régimen de transición a favor de las personas que han cotizado durante la vigencia de las sucesivas modificaciones legales la Corte en la sentencia la T-078 de 2008, reiteró que 
“[...] el Constituyente le confirió al Congreso una amplio margen de configuración política para regular la seguridad social, aquella no es absoluta, pues se encuentra limitada, de manera general, por requisitos formales de trámite y sustanciales que responden a los principios fundamentales del Estado Social de Derecho, y, específicamente por las disposiciones de carácter internacional y el artículo 48 Superior que le impone al momento de reconocer y fijar las condiciones de los derechos, beneficios y prestaciones de la seguridad social, en cumplimiento del principio de progresividad, por un lado, establecer condiciones mínimas que no pueden ser desmejoradas, y por el otro, hacer efectiva la ampliación de los beneficios y la creación de garantías más favorables para la población".

Por medio de la sentencia T-103 de 2008, M.P. Jaime Córdoba Triviño, la Corte estudia la situación de una persona que considera desconocida la protección especial de las personas inválidas y de la tercera edad. Dicha vulneración surge de un error en la fecha de inicio de sus incapacidades que determinan la estructuración de la invalidez. Según la accionante, estas incapacidades iniciaron el 3 de mayo de 2003 y en esa medida los 180 días continuos de incapacidad se cumplían el 3 de noviembre del mismo año. Por lo anterior, para la patente, el régimen aplicable es el artículo 39 de la Ley 100 de 1993, y no la Ley 860 de 2003 (como lo alega el ISS) porque para el momento de la estructuración de la invalidez dicha ley no estaba aún vigente.

La autoridad competente certificó que la invalidez se estructuró el 27 de diciembre de 2003 y la entrada en vigencia de la Ley 860 de 2003 se dio el 26 de diciembre del mismo año, por lo tanto, se tiene que fue el día inmediatamente anterior a la estructuración de la invalidez, por lo que la Corte da por cumplido este requisito.

De igual manera, se señaló que el nuevo régimen resulta prima facie contrario al principio de progresividad de los derechos sociales. Sin embargo, la comprobación de la regresividad de la medida adoptada por la Ley 860 de 2003 es propia de un juicio de constitucionalidad abstracto, por lo que el juez de tutela carece de competencia para realizar una declaración en este sentido. En consecuencia, dispuso que no era suficiente constatar las dificultades sobre la regresividad de la medida, sino que era necesario que concurran otras circunstancias de orden fáctico que deben verificarse en los casos concretos.

Para el caso en concreto, la Corte ordenó el reconocimiento y pago de la pensión de invalidez a favor de la accionante, con base en el régimen consagrado en el artículo 39 de la Ley 100 de 1993 en su versión original.

En sentencia C-428 de 2009, M.P. Mauricio Gonzáles Cuervo, la Corte tuvo la oportunidad de estudiar la demanda presentada contra los numerales 1 y 2 del artículo primero de la Ley 860 de 2003, y en dicha ocasión reafirmó la importancia del principio de progresividad y no regresividad de la legislación. Luego de un riguroso examen de constitucionalidad, la Corte distinguió el contenido del numeral 1 del 2 de la Ley 860 de 2003, y concluyó que

De la comparación del artículo lo de la Ley 860 acusado, frente al artículo 39 inicial de la Ley 100, respecto de los requisitos de semanas mínimas de cotización y el tiempo en que tales semanas se debieron haber cotizado, se concluye que la norma acusada no vulnera el principio de progresividad pues: i) da un mismo tratamiento a todos los afiliados, a diferencia de lo que ocurría en el artículo 39 de la Ley 100 de 1993, y ii) tiene en cuenta la realidad del 
mercado laboral a diferencia del artículo 39 inicial de la Ley 100, establece exigencias que resultan inferiores a la densidad de cotización del sistema pensional colombiano.

Respecto del requisito de fidelidad, la Corte señaló:

Lo anterior permite apreciar cómo este requisito de fidelidad no logra desvirtuar la presunción de regresividad, a diferencia del anterior caso analizado, respecto del cual la reforma mostró matices de progresividad a pesar del aumento en el número de semanas requeridas. A pesar de poder tener un fin constitucional legítimo, en tanto buscaría asegurar la estabilidad financiera del sistema pensional mediante la cultura de afiliación y disminución del fraude, la norma no es conducente para la realización de dichos fines al imponer una carga mayor a las personas a quienes no se les había exigido fidelidad los afiliados de la tercera edad.

En este punto, se reiteró la línea jurisprudencial (Sentencias T-287, T-145, T-110, T-104, T-103, T-080, T-078, T-077, T-069 y T-018 de 2008; T-1072, T-699A, T-641, T-580 y T-043 de 2007; T-221 de 2006 y T-1291 de 2005) sostenida en numerosos casos de tutela, en los cuales no se ha aplicado la disposición demandada por resultar manifiestamente contraria a la progresividad de los derechos sociales consagrada por el constituyente.

La Corte declaró exequible el numeral 1 del artículo 1 de la Ley 860 de 2003, salvo la expresión:

"[...] y su fidelidad de cotización para con el sistema sea al menos del veinte por ciento (20\%) del tiempo transcurrido entre el momento en que cumplió veinte (20) años de edad y la fecha de la primera calificación del estado de invalidez", por considerarla contraria a la Constitución. Y así mismo declaró exequible el numeral 2 del artículo 1 de la Ley 860 de 2003, salvo la expresión "y su fidelidad de cotización para con el sistema sea al menos del veinte por ciento (20\%) del tiempo transcurrido entre el momento en que cumplió veinte (20) años de edad y la fecha de la primera calificación del estado de invalidez".

De esta forma fue expulsado del ordenamiento el requisito de la fidelidad, dejando como única exigencia para el reconocimiento de la pensión de invalidez el haber cotizado un mínimo de 50 semanas durante los tres años anteriores a la fecha de la estructuración de la invalidez.

Mediante sentencia T-710 de 2009, M.P. Juan Carlos Henao Pérez, se analiza el amparo solicitado por una persona que registra una pérdida de su capacidad laboral del $65,75 \%$, a quien se le negó la pensión de invalidez, por existir un conflicto de multi-afiliación. Resuelto dicho inconveniente, se señaló que el reconocimiento de la prestación le correspondía al banco BBVA- Horizonte, quien con posterioridad negó la pensión de invalidez bajo el argumento de no reunir las 26 semanas de cotización dentro del año anterior a la estructuración de la invalidez, conforme a lo dispuesto por la Ley 100 de 1993.

La Corte reitera que el concepto de progresividad no puede admitir la existencia de una regresividad en cuanto a las prestaciones concedidas por el Estado, ya que una medida de esa naturaleza, se entendería como no ajustada a la Constitución. Sin embargo, señaló la Corte:

[...] lo anterior no significa que las autoridades encargadas de regular lo concerniente a los derechos sociales no pueden dar marcha atrás frente a un nivel de protección previamente otorgado. En estos casos, la jurisprudencia ha establecido que no toda regulación más estricta de la forma de satisfacer un derecho social significa 
que hay marcha atrás en ese campo, como ocurre cuando se contempla un incremento en las cotizaciones para la seguridad social, pues en este caso el aumento no puede entenderse per se, sino como una necesaria actualización de las contribuciones necesarias para mantener viable el sistema".

En este fallo, la Corte aclaró que, por regla general, el régimen jurídico aplicable a un caso en concreto, es el que se encuentra vigente al momento de estructurarse la invalidez. Sin embargo, no resulta siempre clara a la hora de ser aplicada, motivo por el cual es oportuno referirse al principio de la favorabilidad, para resolver las dudas que la aplicación de la ley laboral. Conforme a lo anterior se reconoce la pensión de invalidez de acuerdo a lo establecido en el artículo 1, numeral 1 de la Ley 860 de 2003.

Nuevamente, en sentencia T-048 de 2010, M.P. Gabriel Mendoza Martelo, se decide la acción de tutela de una persona con incapacidad correspondiente al 83,80\%, a quien la entidad accionada le niega la pensión de invalidez por no cumplir con el requisito del artículo 1 de la Ley 860 de 2003, que trata sobre la fidelidad al sistema.

En esta oportunidad la Corte distingue dos momentos: 1) antes de proferir la sentencia C-428 de 2009, en que señalaba que el artículo 1 de la Ley 860 de 2003 resultaba contrario al principio de progresividad establecido en el artículo 48 de la Constitución Política, pues de un régimen favorable —-donde se exigían 26 semanas de cotización en cualquier tiempo- se pasó a uno más gravoso en donde no solo se aumentan las semanas de cotización a 50, sino que, además, se adiciona el nuevo requisito de fidelidad. Desde esta perspectiva, la solución que se debía dar a los casos en donde se evidenciara, que las exigencias establecidas en el artículo 1 de la Ley 860 de 2003, aparecían desproporcionadas e irracionales, era la no aplicación del artículo, recurriendo a la excepción de inconstitucionalidad regulada en el artículo 4 de la Constitución Política de 1991. 2) A partir de la sentencia C-428 de 2009, en donde el requisito de fidelidad exigido en el artículo 1 de la Ley 860 de 2003, para obtener la pensión de invalidez por enfermedad común o por accidente, fue declarado inexequible pues dicho requisito hacía más riguroso el acceso a la pensión de invalidez, y en consecuencia no logra desvirtuar la presunción de regresividad.

Para el caso concreto, la Corte determina que la actora efectivamente cuenta con una pérdida de la capacidad laboral del $83,80 \%$, por lo que este requisito se encuentra satisfecho, al igual que las 50 semanas de cotización dentro de los tres últimos años anteriores a la estructuración de la invalidez, ordenando se reconozca y pague la pensión de invalidez respectiva.

Mediante la sentencia T-062 de 2011, M.P. Mauricio González. A una persona de 54 años con pérdida de capacidad laboral del 70,75\% estructurada el 27 de enero de 2009, se le negó la pensión aduciendo que no cumplía ni con las 25, ni con las 50 semanas en los tres años anteriores. La Corte consideró que era necesario abstenerse de aplicar las normas vigentes para dar paso a las más favorables en pensión de invalidez, dado que había cotizado 1.126 semanas hasta el 2006, con lo cual se demostraba que cumplía los requisitos del Decreto 758 de 1990, esto es, 300 semanas en cualquier tiempo. Por esta razón ordenó el reconocimiento de la pensión de invalidez. 
Mediante la sentencia T-885 de 2011, M.P. María Victoria Calle, estudió el caso de una persona portadora del VIH-Sida, quien reportaba una pérdida de su capacidad laboral del 66,14\% estructurada el 27 de noviembre de 1998. Agotado el trámite administrativo, se le negó la pensión aduciendo que no cumplía con los requisitos de la Ley 100 de 1993. La Corte Constitucional, teniendo en cuenta que la evaluación de la pérdida de la capacidad laboral se hizo el 19 de noviembre de 2009, fecha hasta la cual la tutelante, trabajó y cotizó, ordenó tener en cuenta esta última fecha, para la cual si reunía los requisitos de la Ley 797. En esos términos concedió la tutela.

Con ocasión de la sentencia T-934 de 2011, M.P. Jorge Ignacio Pretelt, se analizó la situación de una persona de 27 años con pérdida de su capacidad laboral del 68.15\% estructurada el 7 de septiembre de 2006 y a quien se le había negado la pensión por no reunir el requisito de las 50 semanas en los 3 años anteriores (Ley 860 de 2003). La Corte consideró que en este caso, la aplicación literal lesionaba principios como el de la progresividad, debido a que tenía las 26 semanas requeridas antes de la declaratoria de pérdida de la capacidad laboral, por lo que concedió la tutela, sin aplicar la Ley 860 de 2003.

En virtud de la sentencia T-032 de 2012, M.P. Jorge Ignacio Pretelt, la Corte Constitucional se refirió al caso de una persona de 54 años con pérdida de su capacidad laboral del 73,85\% estructurada el 26 de agosto de 1999. Se negó la pensión puesto que no cumplía los requisitos de la Ley 100 de 1993. La Corte consideró que teniendo en cuenta que la actora cotizó al ISS desde que se estructuró la invalidez hasta el 1 de enero de 2011 cuando se dio el dictamen de calificación, esta fecha debía tenerse como referente. Por esta razón concedió la tutela y ordenó reconocer la pensión.

\section{Conclusiones}

Frente a una profusión legislativa tan grande como la colombiana y a los cambiantes intereses que subyacen a las modificaciones normativas, son los principios los llamados a otorgar coherencia y unidad de sentido al ordenamiento jurídico nacional. Ese es el rol que han desempeñado los principios en Colombia, dando origen a los precedentes constitucionales, los cuales en materia salarial y pensional son de obligatoria observancia, lo que justifica estudios como el presente.

En la figura jurídica de la pensión de invalidez el principio de favorabilidad tiende a transformarse en principio de progresividad, impactando la autonomía del legislador, al que con base en la prohibición de retroceso en materia de DESC, le adelanta juicios estrictos de constitucionalidad, cuando expide leyes que consagran cambios regresivos.

La Corte, mediante el principio de progresividad, ha materializado la protección constitucional para ciertos grupos sociales de especial protección frente a los cuales ha revisado con cautela, los cambios normativos evitando los retrocesos. Estos grupos son: personas de la tercera edad, personas portadoras de VIH-Sida, personas jóvenes. 
Del recorrido jurisprudencial antes realizado, se puede concluir la resistencia de las entidades encargadas del reconocimiento de la prestación de la pensión de invalidez para aplicar el principio de progresividad, y su apego irrestricto a la ley, sin consideración a la densidad de semanas cotizadas, actuando en contravía de claros mandatos internacionales y constitucionales.

La Corte Constitucional ha reiterado una y otra vez, la obligatoriedad de atender la hermenéutica constitucional de esta Corporación. No obstante estas directrices, dichas entidades recurren a formalismos y argumentos forzados, intentando salidas paralelas a los precedentes constitucionales, lo que incrementa innecesariamente el uso de la acción de tutela, poniendo en tela de juicio la obligatoriedad del precedente. 


\section{Referencias}

1. Alianza Internacional para la Extensión de la Seguridad Social (2005). Ginebra: OIT.

2. Arango, R. (2005). El concepto de derechos sociales fundamentales. Bogotá: Universidad Nacional de Colombia.

3. Castel, R.(2003). La inseguridad social. Buenos Aires: Manantial.

4. Goyes, I., Hidalgo, M. (2007). Principios del Derecho Laboral: Líneas Jurisprudenciales. Pasto. Universidad de Nariño. Segunda Edición.

5. Goyes, I., Hidalgo, M. (2012). Principios de la Seguridad Social en Pensiones. Pasto. Universidad de Nariño.

6. Organización Internacional del Trabajo (1999). Trabajo Decente. Memoria del Director General. Ginebra: O.I.T.

7. Organización Internacional del Trabajo (2002). Seguridad Social: Un nuevo consenso. Ginebra: OIT

8. Organización Iberoamericana de la Seguridad Social (1976). Revista No. 1. Madrid.

9. Organización de Estados Americanos (1988). Protocolo de San Salvador. Extraído el 7 de abril de 2011 desdehttp://www.oas.org/juridico/spanish/tratados/a-52.html

10. Naciones Unidas. (1966) pacto internacional de derechos económicos, sociales y culturales. 1976. Extraído el 15 de enero de 2011 desdehttp://www.cinu.org.mx/onu/documentos/pidesc.htm

11. Principios de Limburgo. (1986). Sobre la aplicación del pacto internacional de derechos económicos, sociales y culturales. Extraído el 20 de mayo de 2012 desde

12. http://www.pgjdf.gob.mx/temas/4-6-

13. Rojas - Rojas, Augusto. (2006). Los principios en el derecho.Revista Pensamiento Jurídico No. 16. Bogotá: Universidad Nacional de Colombia.

14. Uprimny, Rodrigo (2000). El bloque de constitucionalidad en Colombia. Un análisis jurisprudencial y un ensayo de sistematización doctrinal.Extraído el 18 de abril de 2009 desde http:www.ilo.org.co

15. Ramelly, A (2003). Sistema de Fuentes del Derecho Internacional Público. Bloque de Constitucionalidad. En Anuario de Derecho Constitucional.1a. Edición. Bogotá: Universidad Externado de Colombia. 


\section{Jurisprudencia corte constitucional}

16. Republica de Colombia. Corte Constitucional de Colombia. Sentencia T-1133 de 2000, M.P. Carlos Gaviria Díaz

17. Republica de Colombia. Corte Constitucional de Colombia Sentencia T-290de 2005, M.P. Marco Gerardo Monroy Cabra

18. Republica de Colombia. Corte Constitucional de Colombia Sentencia T-1291 de 2005, M.P. Clara Inés Vargas Hernández

19. Republica de Colombia. Corte Constitucional de Colombia Sentencia T-103 de 2008, M.P. Jaime Córdoba Triviño

20. Republica de Colombia. Corte Constitucional de Colombia Sentencia C-428 de 2009, M.P. Mauricio Gonzáles Cuervo

21. Republica de Colombia. Corte Constitucional de Colombia Sentencia T-710 de 2009, M.P. Juan Carlos Henao Pérez

22. Republica de Colombia. Corte Constitucional de Colombia Sentencia T-710 de 2009, M.P. Juan Carlos Henao Pérez

23. Republica de Colombia. Corte Constitucional de Colombia Sentencia T-048 de 2010, M.P. Gabriel Mendoza Martelo

24. Republica de Colombia. Corte Constitucional de ColombiaSentencia T-062 de 2011 M.P. Mauricio González

25. Republica de Colombia. Corte Constitucional de ColombiaSentencia T-885 de 2011 M.P. Maria Victoria Calle

26. Republica de Colombia. Corte Constitucional de ColombiaSentencia T-934 de 2011 M.P. Jorge Ignacio Pretelt

27. Republica de Colombia. Corte Constitucional de ColombiaSentencia T-032 de 2012 M.P. Jorge Ignacio Pretelt 